\title{
Inspecting the Properties of Polypropylene/ Poplar Wood Flour Composites with Microcrystalline Cellulose and Starch Powder Addition
}

\author{
Alireza Asgari, ${ }^{\text {a }}$ Amirhooman Hemmasi, ${ }^{\text {a, } *}$ Behzad Bazyar, ${ }^{\text {a }}$ Mohammad Talaeipour, ${ }^{\text {a }}$ \\ and Amir Nourbakhsh ${ }^{\mathrm{b}}$
}

Biocomposites composed of polypropylene (PP) poplar wood flour (WF) $(0 \%$ and $20 \%$ ), microcrystalline cellulose (MCC) $(0 \%, 2 \%$, and $6 \%)$, and starch powder (SP) $(0 \%, 5 \%$, and $10 \%)$ were examined. The mechanical, physical, biodegradability, and morphological properties were assessed. The mechanical properties, water absorption (WA), thickness swelling (TS), and biodegradability were improved by adding WF to PP. By increasing MCC and SP, the composite modulus of rupture (MOR), modulus of elasticity (MOE), tensile modulus, WA, TS, and biodegradability increased. The tensile strength increased by increasing MCC, while the opposite was true for SP. An increase in WA and TS of composite, would decrease static contact angle. The morphological studies indicated that by adding MCC and $\mathrm{SP}$, the composite stress transfer and distribution ability and structural bonding of the composite improved. By increasing the biodegradability and reducing the sample weights, the extent of surface degradability increased.

Keywords: Wood flour; Microcrystalline cellulose; Starch powder; Properties; Biodegradability

Contact information: a: Department of Wood and Paper Science and Engineering, Faculty of Natural Resources and Environment, Science and Research Branch, Islamic Azad University, Tehran, Iran; b: Department of Wood and Paper Science, Research Institute of Forests and Rangelands (RIFR), Tehran, Iran; *Corresponding author: $h \_$hemmasi@ srbiau.ac.ir

\section{INTRODUCTION}

Plastic accumulation and plastic products cause catastrophic effects on wildlife and human nutrition (Aganguly 2018). Most plastic products are used only once and then disposed of by consumers. These plastics release harmful chemicals into soil, which then enters the superficial and other water resources. The species drinking from these waters are exposed to potentially fatal dangers. Animals are exposed to intoxication by plastic pollution, which in turn affects human nutrition (Subba Reddy et al. 2014). One possible solution to such pollution is the use of additives to non-biodegradable polymers (Zuchowska et al. 1998). For this purpose, different materials like rice husk (Suharty et al. 2014), coire (Verma et al. 2013), curaua fibers (Beltrami et al. 2014), natural textile fibers (Todor et al. 2018), and more unusual materials like keratin extracted from chicken feather waste (Oladayo et al. 2016) and fish waste (Nourbakhsh et al. 2014) are applied. Bio-based plastics are made when a biodegradable polymer is combined with a synthetic polymer; natural polymers including starch and cellulose can be applied (Liu et al. 2003).

The application of wood fiber-reinforced plastic composites or other lignocellulosic materials is increasing (Ashori 2008). Natural fillers provide advantages such as appropriate price and degradability. One of the most common plant fibers applied in the 
thermoplastic industry is wood flour (WF), which is produced from developed resources like plant pruning and sawdust in a commercial manner (Salemane and Luyt 2006). The application of wood plastic composites in construction is limited to flooring, railing, docks, and fencing because they lack the modulus of rupture (MOR) and modulus of elasticity (MOE) necessary to withstand heavy load as construction materials (Lu et al. 2000). Different approaches are adopted to enhance the mechanical properties of wood plastic composites (WPCs) by applying fillers, and changing the size of the particles is the main approach (Ashori 2012).

Microcrystalline cellulose (MCC) is a cellulose reinforcing agent (Bai and Li 2009), where the fiber diameter is a few micrometers. These fibers are composed of crystalline cellulose microfibrils of $5 \mathrm{~nm}$ width and 20 to $30 \mathrm{~nm}$ length (Lin et al. 2008). The MCC is produced through different methods including reactive extrusion, enzyme mediation, steam explosion, and acid hydrolysis, where the amorphous cellulose fraction is destroyed and the crystalline fraction remains (Hindi 2016). Crystalline cellulose is a more appropriate reinforcing agent than cellulose (Lin et al 2008). Arjmandi et al. (2015) added MCC to the montmorillonite reinforced polylactic acid nanocomposite, showing that adding this material reduces the composite tensile strength; the weight reduction is increased due to biodegradability. Ashori and Nourbakhsh (2010) added 4 and 8\% MCC particles to PP, revealing that the tensile, bending, and impact strengths increase. Adding $2.5,10,20$, and $30 \% \mathrm{MCC}$ to the hybrid matrix made of poly (ethylene terephthalate) and poly (trimethylene terephthalate) increases the tensile strength, elongation at break (until $20 \%$ MCC content), tensile modulus, MOE, and density but reduces impact strength (Kiziltas 2010). Shah and Pandey (2017) added 10, 15, and 20\% MCC to linear low density polyethylene (LLDPE)/titanium dioxide $\left(\mathrm{TiO}_{2}\right)$ composites; the water absorption and sample weight reduction were increased due to biodegradability.

Starch is a polysaccharide made of amylose and amylopectin. This inexpensive material is a biodegradable and recyclable polymer and an appropriate alternative in combination with synthetic polymers (Matzinos et al. 2001). Mousavi et al. (2015) added corn $(46,44,33,21$, and 9\%), starch (10, 20, and 30\%), and eggshell nanoparticles (1, 3, and 5\%) to polypropylene (PP) and found that an increase in weight percentage of these materials in the PP reduces the bending modulus and tensile properties increased when starch with 1, 3, and 5 weight percent of eggshells nano particles was added to the composites. Beg et al. (2016) added 5, 10, 20, and 30\% starch to low-density polypropylene (LDPE) and indicated that an increase in weight percentage of starch in the composites reduces the tensile strengths, but it increases the tensile modulus, MOR, and MOE. Esmaeilzadeh Saieh et al. (2019) studied the physical and biodegradability behavior of the composites by adding 3 and $5 \mathrm{wt}$ \% nanoclay and cellulose nanofibers to composites made of starch thermoplastic polymer (as a matrix) and sawdust (as filler). The results revealed that by increasing cellulose nanofiber to the combination the water absorption and thickness swelling of composites reduce, while the glass transition temperatures, biodegradability, and the connection among starch matrixes increased as a result of the added sawdust. Wilfred et al. (2018) combined 10, 25, 50, 75, and 90\% starch with polylactic acid (PLA) and assessed the weight loss of the produced composites subject to biodegradability within 14 and 28 days of soil burial and compost at 45 and $55{ }^{\circ} \mathrm{C}$. The results indicated that by increasing starch, temperature of the sample biodegradability intensity increases. The samples buried in the compost are exposed to higher biodegradability in relation to the samples buried in the soil. By adding starch to PLA, the 
sample brittleness is increased, while the thermal stability is reduced.

Although there have been some studies applying MCC and starch as components of polymer composites, the effect of applying these biomaterials in WPCs needs further examination. Here, the objective is to assess the effect of adding MCC and SP as a bioreinforcing agent on the mechanical, physical, biodegradation, and morphological properties of the WPCs made of PP and WF.

\section{EXPERIMENTAL}

\section{Composite and Sample Preparation}

The lignocellulosic filler was WF of 40- to 60-mesh particle size, that is, 256 to 400 $\mu \mathrm{m}$. The WF was oven-dried at $105^{\circ} \mathrm{C}$ for $24 \mathrm{~h}$ to remove moisture before the production process. The PP (Poliran P10800) was provided from the Petrochemical Co., Bandar Imam, Iran, and applied as a matrix in the composites. PP pellets had a melt flow index of 7 to 10 $\mathrm{g} / 10 \mathrm{~min}$ and density of $0.90 \mathrm{~g} / \mathrm{cm}^{3}$. MCC fibers (Merck, Darmstadt, Germany) with 3 to $60 \mu \mathrm{m}$ length, 70 to $400 \mathrm{~kg} / \mathrm{m}^{3}$ bulk density, $1.5 \mathrm{~g} / \mathrm{cm}^{3}\left(20^{\circ} \mathrm{C}\right)$ density, $260{ }^{\circ} \mathrm{C}$ flash point, $232{ }^{\circ} \mathrm{C}$ ignition temperature and 5.0 to $7.5\left(100 \mathrm{~g} / \mathrm{L}, \mathrm{H}_{2} \mathrm{O}, 20{ }^{\circ} \mathrm{C}\right.$ ) (slurry) $\mathrm{pH}$ value and $\mathrm{SP}$ particles (Merck Millipore, Darmstadt, Germany) with less than $20 \mu \mathrm{m}$ diameter, $50 \mathrm{~g} / \mathrm{L}$ solubility, $300 \mathrm{~kg} / \mathrm{m}^{3}$ bulk density, max 0.4 sulfated ash, $2 \mathrm{~h}\left(105^{\circ} \mathrm{C}\right)$ loss on drying and 6.0 to $7.5\left(20 \mathrm{~g} / \mathrm{L}, \mathrm{H}_{2} \mathrm{O}, 25{ }^{\circ} \mathrm{C}\right)$ were applied as micro additives. The scanning electron microscopy (SEM) images of the applied MCC fibers and SP particles are illustrated in Fig. 1.
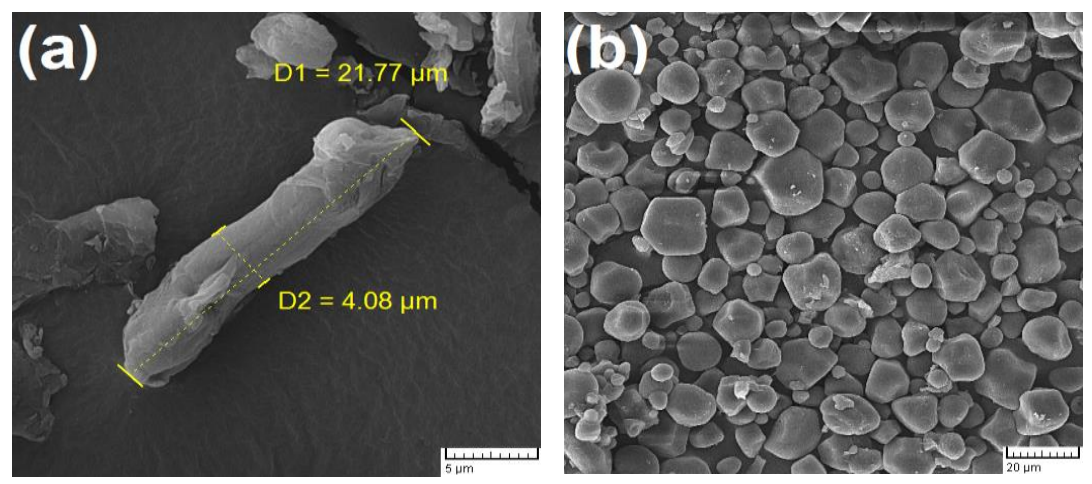

Fig. 1. Scanning electron microscopy (SEM) image of the a) applied MCC fibers and b) applied SP particles

Polypropylene-graft-maleic anhydride (PP-g-MA) (Eastman Chemical, Kingsport, TN, USA) with $16 \mathrm{mg} \mathrm{KOH} / \mathrm{g}$, and molecular weight of 60.000 was used. The formulation and applied volumes of the composite components are tabulated in Table 1.

To produce experimental samples, the MCC fibers and SP particles are added to the PP matrix and combined through a twin screw extruder machine (Werner and Pfleiderer, Model: ZSK25, Frankfurt, Germany, L/D: 40, D: 25 CM). The temperature in the twin screw extruder machine was $180^{\circ} \mathrm{C}$ with a rotation of $40 \mathrm{rpm}$. The produced cakes were ground and converted into granules, which were then combined with WF and chemical coupling agent in a Haake internal mixer (HBI SYS 90, Overland Park, Kansas, United States of America) at $180{ }^{\circ} \mathrm{C}$ at $60 \mathrm{rpm}$ for $8 \mathrm{~min}$ for each sample. The produced 
materials were transferred again into the grinder to be converted into granules. These granules were placed at room temperature for $2 \mathrm{~h}$ to cool completely and then, in an oven at $105{ }^{\circ} \mathrm{C}$ for $24 \mathrm{~h}$ to dry completely. Finally, the samples were run through an injection molding machine (Aslanian, Model: EM 80, Tehran, Iran) at $180{ }^{\circ} \mathrm{C}$ and injection pressure of $4 \mathrm{MPa}$. The plates intended for the biodegradable experiments were provided through a hot press machine (Toyoseiki, Model WCH, Tokyo, Japan). The granules were poured into a $100 \mathrm{~cm}^{2}$ plate mold in an even manner, placed in a press molding device, preheated at $180{ }^{\circ} \mathrm{C}$ for $5 \mathrm{~min}$, and hot pressed at $5 \mathrm{mega}$ Pascal (MPa) pressure for $1 \mathrm{~min}$.

Table 1. Formulation and Applied Volumes of the Composite Components

\begin{tabular}{|c|c|c|c|c|c|}
\hline \multirow{2}{*}{ Sample Code } & \multicolumn{5}{|c|}{ Composition of Samples (per total weight, \%) } \\
\cline { 2 - 6 } & PP & PWF & MAPP & MCC & PSP \\
\hline Pure PP & 100 & 0 & 0 & 0 & 0 \\
\hline 1 & 77 & 20 & 3 & 0 & 0 \\
\hline 2 & 75 & 20 & 3 & 2 & 0 \\
\hline 3 & 71 & 20 & 3 & 6 & 0 \\
\hline 4 & 72 & 20 & 3 & 0 & 5 \\
\hline 5 & 67 & 20 & 3 & 0 & 10 \\
\hline 6 & 70 & 20 & 3 & 2 & 5 \\
\hline 7 & 65 & 20 & 3 & 2 & 10 \\
\hline 8 & 66 & 20 & 3 & 6 & 5 \\
\hline 9 & 61 & 20 & 3 & 6 & 10 \\
\hline
\end{tabular}

\section{Methods}

All experiments for tensile strength and tensile modulus were conducted according to ASTM D 638-14 (2015). The MOR and MOE were tested according to ASTM D 79017 (2017). An Instron universal testing machine (model 1186, Norwood, MA, USA) was used. The WA and TS were tested according to ASTM D 570-98 (2018) and static contact angles were tested according to ASTM D 7334 by a Jikan CAG-20 test machine (Jikan Surface Nano-Engineering Company, Tehran, Iran). A soil burial test was run according to Behjat et al. (2009). Each experiment for each sample consisted of five iterations. All experiments were run in environmentally controlled (relative humidity of 50\%) conditions. The statistical analysis was performed using SPSS Ver. 11.5 software (IBM, Armonk, NY, USA).

\section{Water Absorption and Thickness Swelling}

To measure the WA and TS, the sample weights and thicknesses were measured. The prepared samples were placed in distilled water at room temperature for 2 and $24 \mathrm{~h}$. After being removed from the water, these samples were dried with a cloth and the measurements were repeated. The WA percentage of the experimental samples was calculated through the following equation,

$$
\text { WA }(\%)=100 \times\left(M_{2}-M_{1}\right) / M_{1}
$$

where WA is the water absorption and $M_{1}$ and $M_{2}$ are the sample weights before and after absorbing water, respectively. The thickness swelling of the experimental samples was calculated through the following equation,

$$
\operatorname{TS}(\%)=100 \times\left(T_{2}-T_{1}\right) / T_{1}
$$


where TS is the thickness swelling and $T_{1}$ and $T_{2}$ are the sample thicknesses before and after absorbing water, respectively. To assess the composite's long time WA and TS, the experimental samples were placed in distilled water for $720 \mathrm{~h}$. The WA and TS were measured after being removed from the water through the described methods.

\section{Soil Burial Test}

The soil for burying the experimental plates was collected from Halghe Dare landfill site, city of Karaj, Alborz province, Iran. This soil was transferred to the laboratory and poured into the POT. Square plates in $10 \mathrm{~cm} \times 10 \mathrm{~cm} \times 0.1 \mathrm{~cm}$ dimensions were buried within $10 \mathrm{~cm}$ depth of the soil. The area encompassing the soil and the experimental samples was maintained at $27{ }^{\circ} \mathrm{C}$ and 45 to $60 \%$ humidity. The POTs were covered with plastic films to prevent water evaporation from the soil surface. The biodegradability of the samples was measured by measuring their weight changes after burial in the soil by considering the passage of time.

The samples were removed from the soil every 20 days, washed with water to clean the particles on the surface, and oven-dried at $105 \pm 5{ }^{\circ} \mathrm{C}$ for $24 \mathrm{~h}$. The dried samples were weighed on an electron scale at $0.1 \mathrm{mg}$ accuracy to compare the weight reduction. The sample weights were normalized at $10 \mathrm{~g}$ at the primary measurement.

\section{Morphological Studies}

The fracture surface of tensile specimens together with the degraded surfaces of the soil burial test (SBT) samples were observed by scanning electron microscopy (SEM) (VEGA TESCAN, Kohoutovice, Czech Republic).

\section{RESULTS AND DISCUSSION}

\section{Mechanical Properties}

The experimental sample tensile properties including tensile strength and tensile modulus are illustrated in Fig. 2. By adding WF to the matrix, the tensile strength and tensile modulus increased in relation to the pure PP. This phenomenon is predictable because as usual the tensile properties of PP increase by adding wood fillers to it. The wood filler in PP transfers and distributes the tension imposed on the composite in the matrix material (Farsi 2010). The results obtained by Kokta et al. (1989) and Mijiyawa et al. (2014) correspond to this result. By increasing the MCC in the multi-structure composition, the tensile strength and tensile modulus increased in relation to the sample 1. By adding and increasing SP in the composition, the tensile strength decreased in relation to the sample 1 in a significant manner, while the opposite was true for the tensile modulus. The highest tensile strength was measured in sample 3 with the highest MCC (6\%) and lowest SP (0\%); the lowest tensile strength was measured in sample 5 with the lowest MCC $(0 \%)$ and highest SP (10\%). The highest tensile modulus was measured in sample 9 with the highest MCC and SP percentages in the composition, which were increased in relation to the sample 1. The improvement of tensile strength in the presence of cellulose materials is predictable because these materials are firmer than the polymer matrixes, and this firmness is transferred to the composite (Salemane and Luyt 2006). Ashori and Nourbakhsh (2010) obtained similar results. 
By the entrance and increase in SP in the composition, the composite tensile strength was reduced, because the pure starch tensile strength is $90 \%$ lower than that of pure PP (Oduola and Akpeji 2015), therefore, a decrease in PP weight percentage in composite structure and replacing it with starch, the final tensile strength of the composites containing starch would reduce. The tensile modulus is increased because pure starch is very flexible (Oduola and Akpeji 2015) and may increase the flexibility by entering the composite, consequently increasing the tensile modulus. Mousavi et al. (2015) obtained different results that might be due to differences in the composition of the composites and the different volumes of materials used.

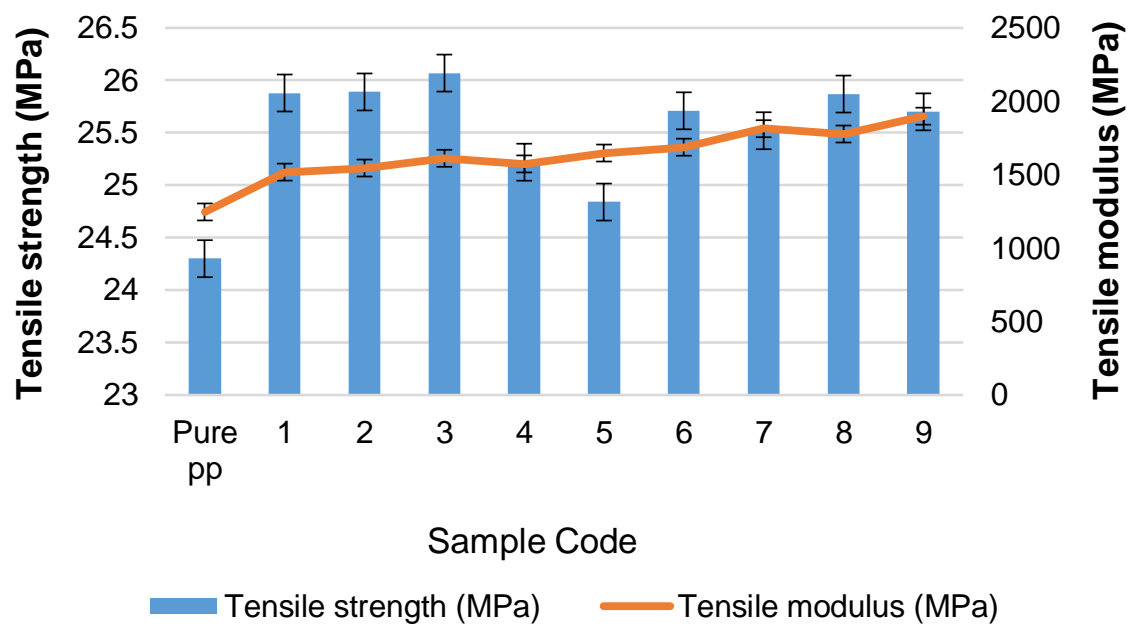

Fig. 2. Tensile strength and tensile modulus results of tested composites

The results obtained from the bending experiments are illustrated in Fig. 3. By adding WF to the matrix, the modulus of rupture (MOR) and modulus of elasticity (MOE) volumes increased in relation to the pure PP.

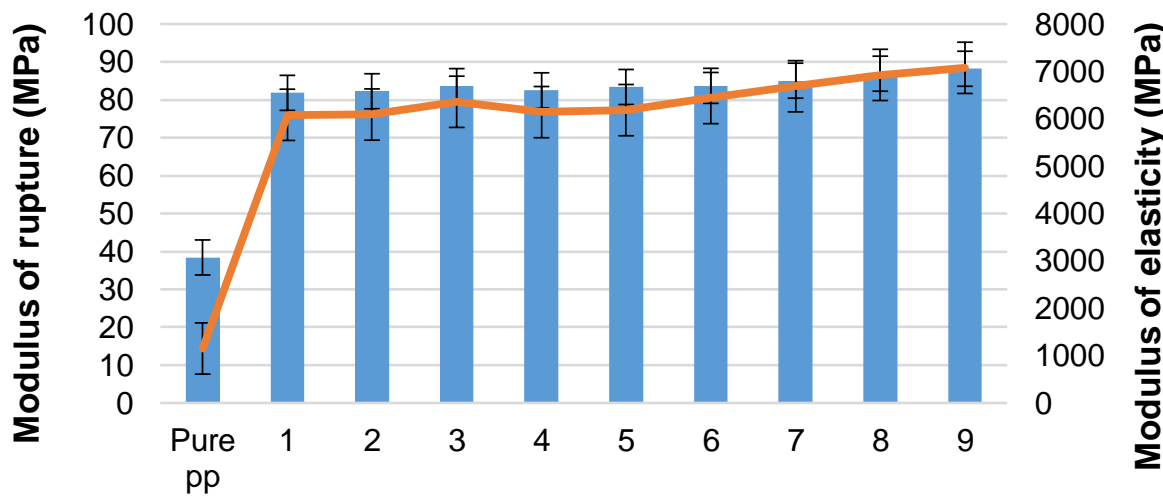

Sample Code

Modulus of rupture (MPa) $\quad$ Modulus of elasticity (MPa)

Fig. 3. Modulus of rupture (MOR) and modulus of elasticity (MOE) results of tested composites 
In general, by adding wood fillers to the polymetric matrix the bending properties of the produced composite improve in relation to the pure polymer, because the composites' properties are affected by the properties exclusive to each component. Wood is stronger and firmer than the common polymers applied in the composition of woodplastic composites, such as PP, and it contains a higher volume of bending strength in relation to these polymers (Klyosov 2007). Consequently, by entering the polymer matrix, wood can improve the bending properties. Increasing the WF weight percentage from 30 to 35 in the composites made of PP matrix material increases the composites' MOR and MOE (Tabarsa et al 2011). Gozdecki and Wilczynski (2015) reported an increase in MOE due to an increase in WF in composites made of PVC matrix material. By adding and increasing $\mathrm{MCC}$ and SP in a separate manner in the multi-structure combinations, MOR and MOE increase in relation to the sample, while by increasing MCC and SP in a simultaneous manner, the MOR and MOE increase in relation to the sample 1 in a significant manner. In sample 9, which had the highest MCC and SP weight percentages in the composites' combination, the highest MOR and MOE volumes were obtained. According to Ashori and Nourbakhsh (2010), by adding MCC to the PP matrix, the MOR increases. MCC particles constitute high aspect ratio (length to diameter ratio). It is revealed in many studies that by increasing the fibers' aspect ratio, the tensile and bending strengths together with the modules related to the multi-structure products increase. Aspect ratio is the most effective on the strength and stiffness of WPCs made of WF and PP (Stark and Rowlands 2003). Pure starch has high bending strength and is flexible; hence, by entering a PP matrix material, increases the bending properties thereof and behaves as a stiffening agent (Oduola and Akpeji 2015). Mousavi et al. (2015) obtained different results and found that by increasing the weight percentage of starch in produced composites, the bending properties decreased, while contrary to their finding. In this study an increase in starch weight percentage increased the composite bending strength.

\section{Water Absorption, Thickness Swelling and Static Contact Angle}

The WA and TS volumes are illustrated in Figs. 4 and 5, respectively. By adding WF to the PP matrix, the WA and TS volumes increased in short ( 2 and $24 \mathrm{~h}$ ) and long $(720 \mathrm{~h})$ terms in relation to pure PP. In general, WPCs has higher WA in relation to pure polymer (Klyosov 2007), because wood, due to the $\mathrm{OH}$ groups in its structure, is hydrophilic (Wang et al. 2013). By increasing the WF volumes in the composite combination, the WA spots increase; thus, an increase in the composite's WA capacity (Bhaskar et al. 2012). Adding MCC and SP to the composite combination in both separate and simultaneous manners increased the WA and TS, while the static contact angle decreased in the produced composites, indicating that with increasing of WA and TS of composites, wettability and hydrophilic properties of their surface area increased (Fig. 6). The lowest WA and TS volumes were observed in pure PP of to the sample 1 with the lowest MCC $(0 \%)$ and SP $(0 \%)$ volumes, while the highest WA and TS volumes were measured in sample 9 samples with the highest MCC $(6 \%)$ and SP (10\%) volumes, where after $720 \mathrm{~h}$ immersion into distilled water, an increase is observed in relation to the sample 1. The lowest static contact angle (Most wettability and hydrophilic of surface) is observed in sample 9 (Fig. 6) with most content of bio fillers in composition. The biggest disadvantage of cellulose fibers is their moisture absorption in relation to the synthetic fibers. Due to hydroxyl groups in the cellulose structure, these fibers tend to absorb moisture, leading to swelling (Madsen and Gamstedt 2013). 


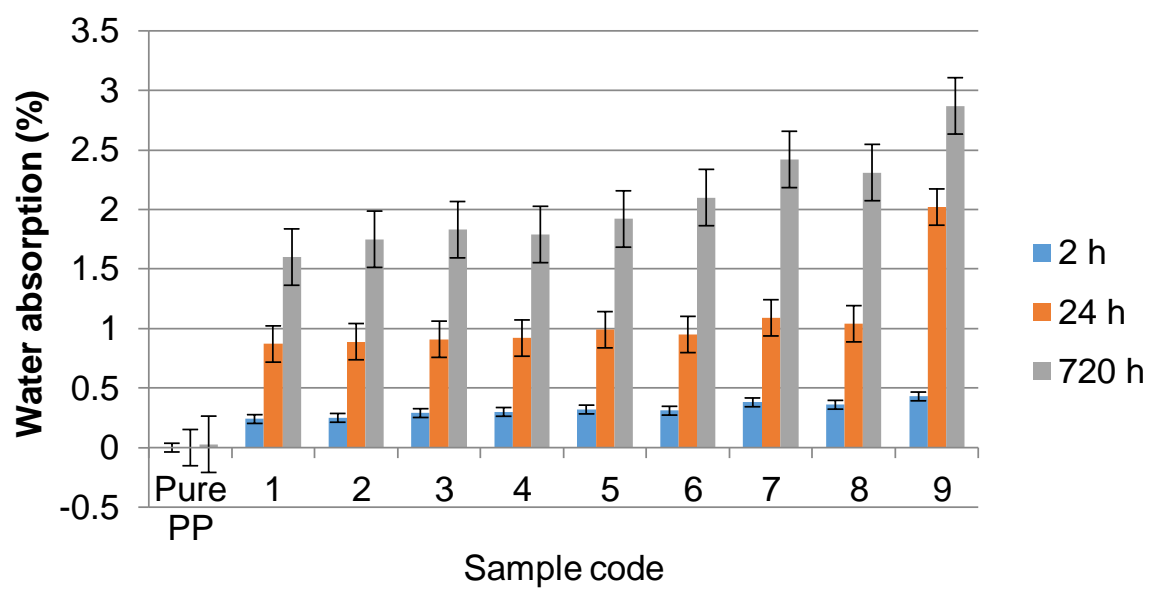

Fig. 4. Composite water absorption of after 2, 24, and $720 \mathrm{~h}$ immersion in water

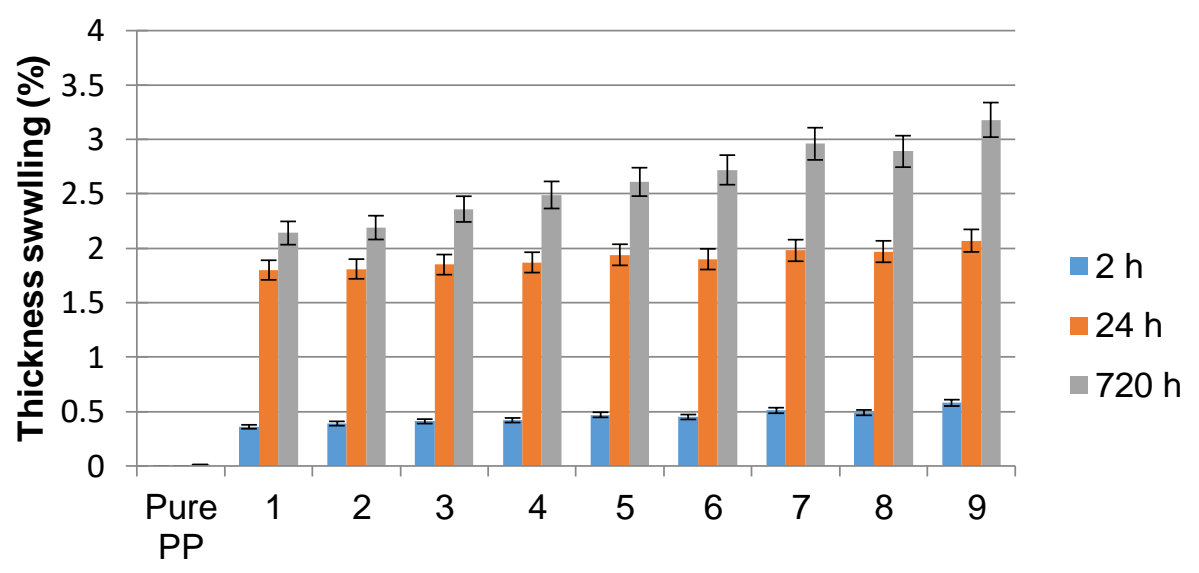

Sample code

Fig. 5. Composite thickness swelling after 2, 24, and $720 \mathrm{~h}$ immersion in water

Starch materials are hydrophilic and contain available hydroxyl groups (Myilsamy et al. 2018), which absorb water by forming hydrogen bonds (Kormin et al. 2017). In composites, these materials can increase the WA and TS. Upon the testable composite submergence time in distilled water for 2 to 24 and $720 \mathrm{~h}$ at the most, their WA and TS levels increase, because, in general, by an increase in the water immersion time, the WA increases (Tay et al. 2014).

\section{Biodegradability}

The soil burial test (SBT) recorded weight reduction rates, as shown in Table 2. In all samples except the pure PP sample, the weight reduction began at the $40^{\text {th }}$ day of the experiment in a gradual manner. By adding WF to the PP matrix, the weight reduction of the experimental samples is increased in relation to the pure PP. Pure PP weight reduction rate after four months of soil burial is 0 . PP is extremely hydrophobic; consequently, the microorganisms cannot attack and feed on its surface (Arutchelvi et al. 2008). 

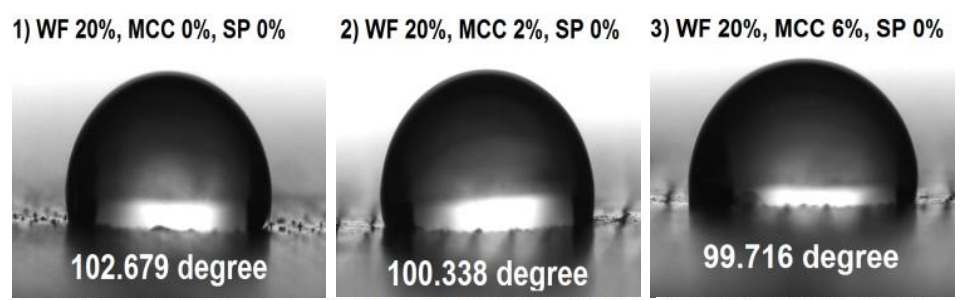

5) WF $20 \%$, MCC 0\%, SP $10 \%$
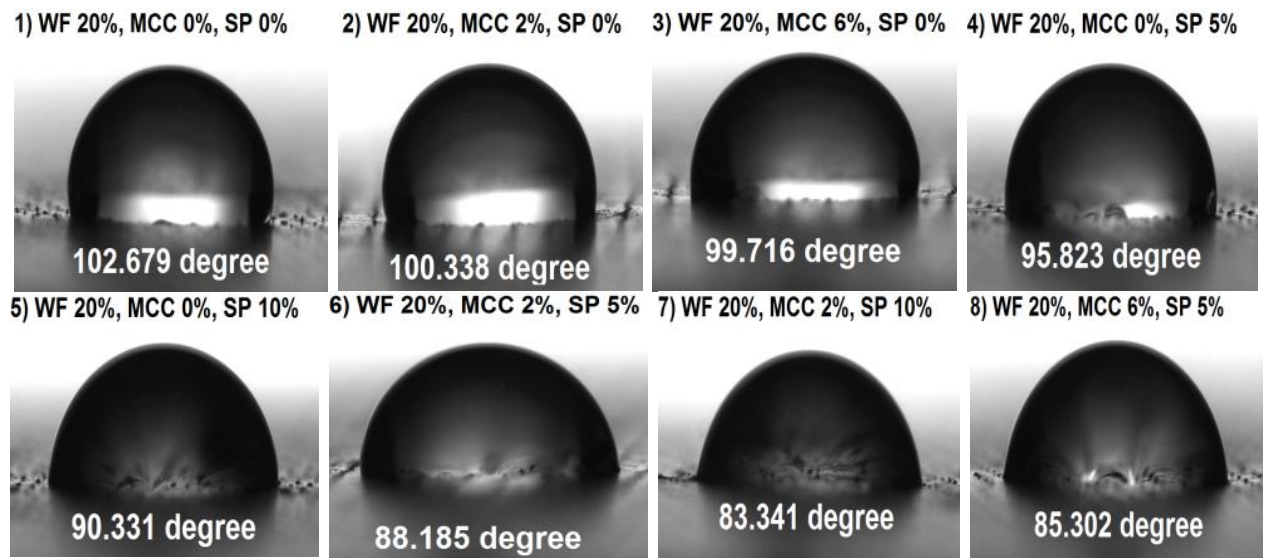

9) WF $20 \%$, MCC 6\%, SP 10\%

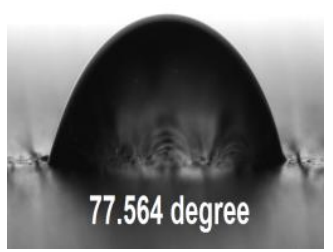

Fig. 6. Static contact angle of composites

Table 2. Soil Burial Test Measured Weight Reduction Rates

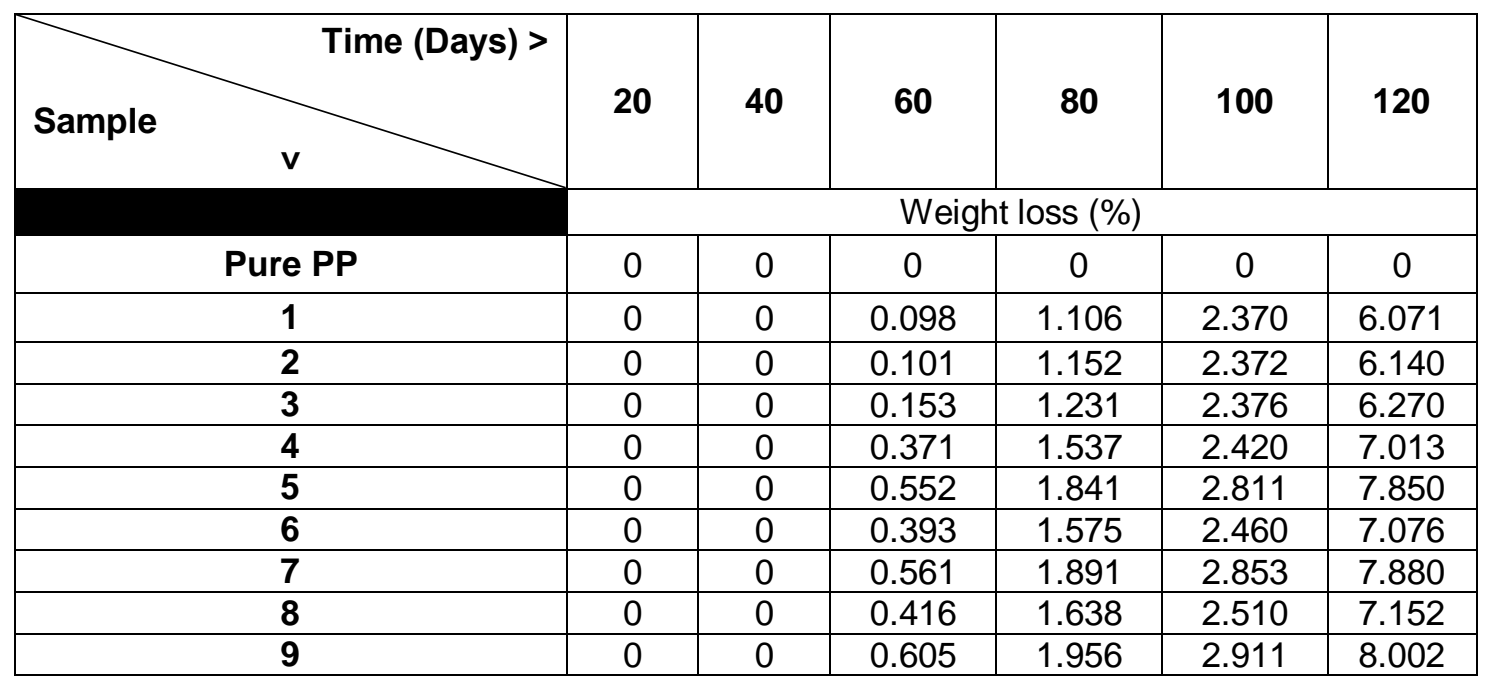

The lignocellulosic materials are biodegradable in nature and when applied as filler in the composite, they affect the biodegradability (Muniyasamy et al. 2013). By adding and increasing $\mathrm{MCC}$ in the composition in a separate manner (samples 2 and 3), the weight reduction is increased in relation to the sample 1. Also by adding and increasing SP in the composite composition (samples 4 and 5) the weight reduction is increased in relation to the sample 1. By adding and increasing MCC and SP together in composition (samples 6, 7, 8, 9) the weight reduction due to biodegradation is increased in relation to the sample 1 . The highest weight reduction was observed at 120 days after soil burial in the samples of the sample 9 containing the highest SP and MCC. The effect of SP in increasing the samples' biodegradability was higher than that of MCC. SP affects the polymer capacity in absorbing 
water molecules together with their physiochemical properties and their susceptibility for biodegradability (Khoramnejadian 2013). MCC has lower WA capacity in relation to cellulose because the $\mathrm{OH}$ reactive groups are extremely low (Nasution et al. 017), leading to a lower biodegradability. Starch is a material with high biodegradability that is consumed by microorganisms (Michad Gould et al. 1990).

\section{Scanning Electron Microscopy}

The fracture surface of the samples together and the degraded surface of the plates applied in the soil burial test were assessed through SEM after removing the plates from the soil (four months of burial). The fillers' ability to connect in the polymer matrix together with their positioning and dispersion in the matrix were evaluated, and the effect of adding fillers to the composite composition on the biodegradability of the plates is assessed.

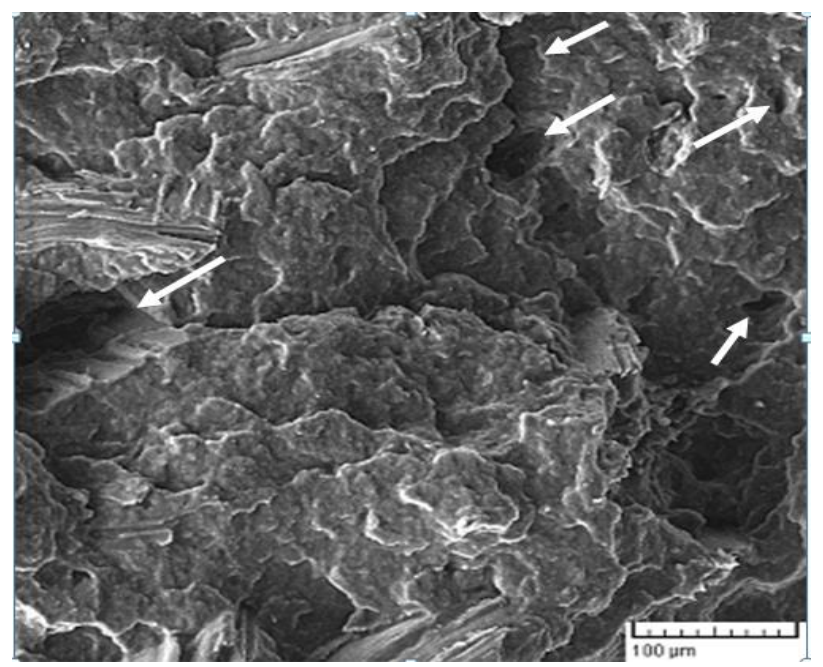

Fig. 7. Fracture surface of the samples containing $20 \%$ WF without MCC and SP (sample 1)

The SEM image of the fracture surface of the samples containing WF without MCC and SP (sample 1) is illustrated in Fig. 7.

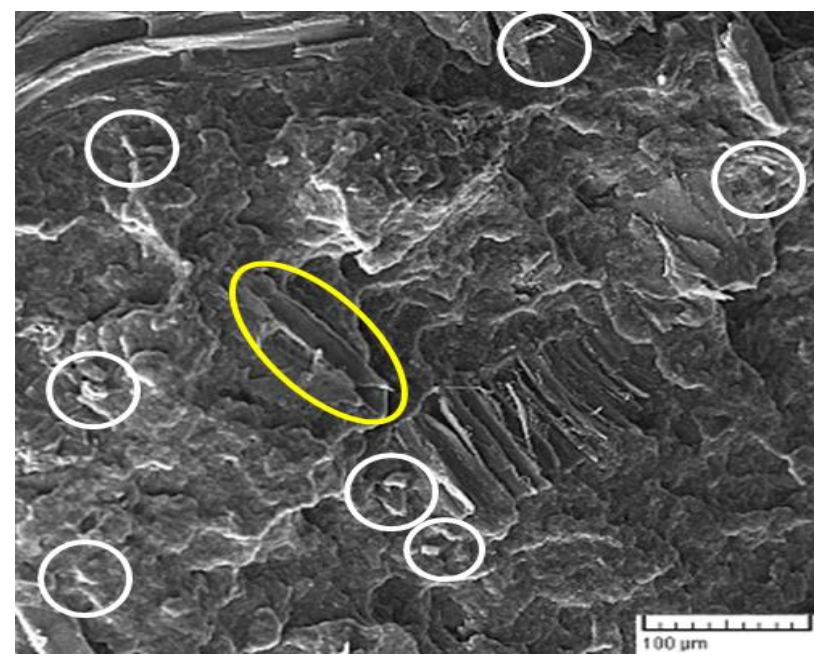

Fig. 8. Fracture surface of sample with $20 \% \mathrm{WF}, 6 \% \mathrm{MCC}$, and $0 \% \mathrm{SP}$ 
The white arrows indicate the holes generated due to the WF particles dropped out of the matrix surface after imposing tension. This particle drop is due to low ability of the composite to transfer and distribute the stress applied to it in the absence of micro-network and lack of micron-scale bio materials (MCC and SP) in the composite structure.

The fracture surface of the sample containing 6\% MCC (sample 3) is illustrated in Fig. 8; there were no holes and cracks caused by the dropping out and separating of WF particles on the sample surface. By adding MCC in the composite, the stress transfer and distribution ability of composite increases and a surface with lower unevenness and higher consistency is obtained. The yellow ellipse indicates the section where one of the filler particles is fractured subject to tension imposition, but it maintains its connection with the matrix and do not separate. The dispersion of MCC fibers in the surface of the specimen is shown by white circles.

The fracture surface of the sample containing 10\% SP (sample 5) is illustrated in Fig. 9. By adding starch to the composition, similar to MCC, the surface unevenness was reduced. The filler particles were not removed from the surface after fracture and maintained their connection with the matrix (yellow ellipse), which is caused by the more stress transfer and distribution ability of composite. The dispersion of SP particles in the surface of the specimen is shown by white circles.

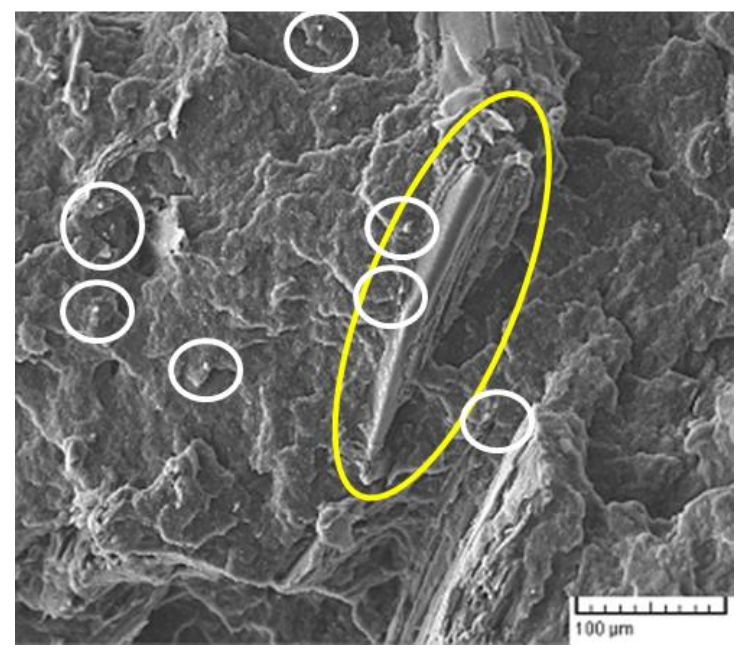

Fig. 9. Fracture surface of sample with $20 \% \mathrm{WF}, 0 \% \mathrm{MCC}$, and $10 \% \mathrm{SP}$

The fracture surface of the sample containing the highest micron-scale bio materials consisting of $6 \%$ MCC and 10\% SP (sample 9) is illustrated in Fig. 10. The sample had a smooth and even surface in relation to the other samples. The holes and unevenness caused by the WF particles' dropping out and separating from the polymer matrix was eliminated completely, which indicates the highest and most ability of composite to resist the imposed stresses in presence of highest volumes of micron-scale bio materials (MCC and SP). These micron-scale materials are placed inside the cavities in the composite resulting from the incorporation of the wood flour with the matrix to reduce porosity and increase the structural bonding of the composite by incorporating micro-cavities in the composite, thereby enhancing bonding between the composite components. 


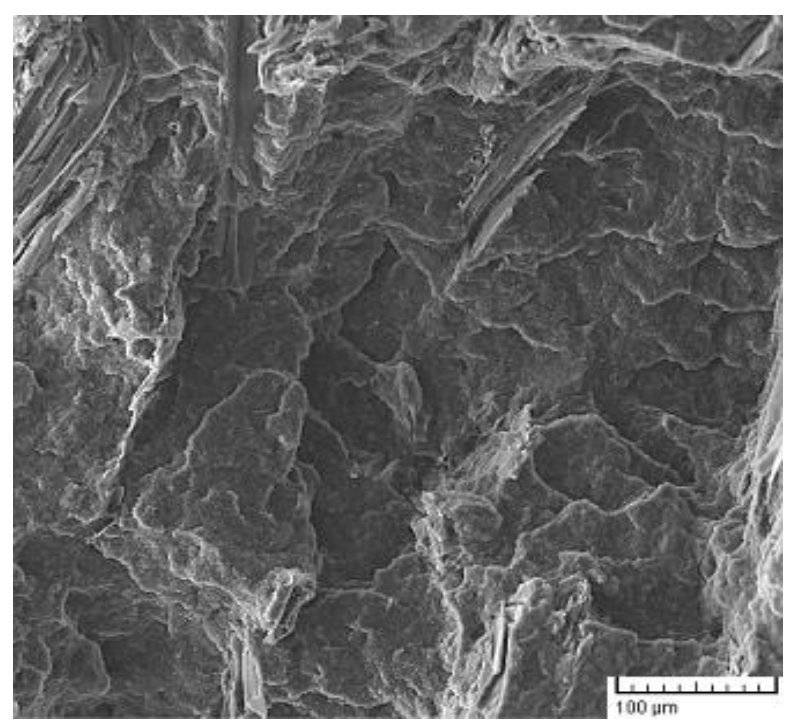

Fig. 10. Fracture surface of the sample with $20 \% \mathrm{WF}, 6 \% \mathrm{MCC}$, and $10 \% \mathrm{SP}$

The soil burial test samples removed from the soil four months after the burial were assessed through SEM, as shown in Fig. 11. The results indicated that the samples containing a higher weight percentage of bio-micro-fillers (MCC and SP) had more holes, cracks, and surface fractures subject to biodegradability. As observed in the image of the sample 1 (Fig. 11a; 20\% WF, 0\% MCC, 0\% SP), some unevenness was generated on the sample surface, which is due to the consumption of the biomaterials in the composite (WF) by the microorganisms. In the image of sample 3 (Fig. 11b;20\% WF, 6\% MCC, 0\% SP), it is observed that near the single holes (white arrows), several big holes close to one another (white circle) were generated, which indicates a higher biodegradability after entering MCC in the composite. As observed in the image of the sample 5 (Fig. 11c; 20\% $\mathrm{WF}, 0 \% \mathrm{MCC}, 10 \% \mathrm{SP}$ ), the fracture surface was increased in relation to the images of the previous samples where degradation is observed as several cracks and unevenness on the surface due to adding $10 \%$ SP to the composite. By assessing the surface of the sample 9 (Fig. 11d), the sample containing the highest bio material consisting of $20 \% \mathrm{WF}, 6 \% \mathrm{MCC}$, and $10 \% \mathrm{SP}$, where the highest weight reduction is reported in the soil burial test sample, a big hole is observed on the sample surface. By assessing the soil burial test images obtained through SEM, after 120 day of being buried it is revealed that the samples containing higher bio filler percentage degrade more at their level, indicative of adding more organic fillers in bio composites increase their biodegradability. 

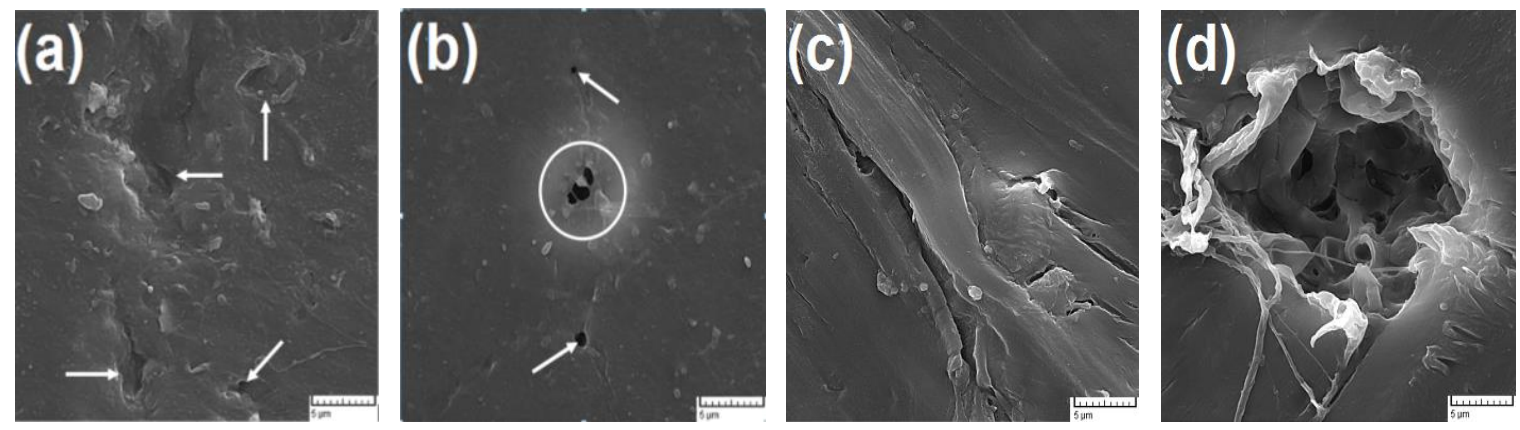

Fig. 11. Biodegraded surface of soil burial test samples removed from the soil four months after the burial. (a) sample 1 with 20\% WF, $0 \%$ MCC and 0\% SP in composition (b) sample 3 with 20\% WF, $6 \%$ MCC and $0 \%$ SP in composition (c) sample 5 with $20 \%$ WF, $0 \%$ MCC and $10 \%$ SP in composition (d) sample 9 with $20 \%$ WF , $6 \%$ MCC and $10 \%$ SP in composition

\section{CONCLUSIONS}

1. Adding wood flour to pure polypropylene (PP) enhanced the composite mechanical properties and biodegradation, while decreasing moisture properties.

2. By adding and increasing the microcrystalline cellulose (MCC) weight percentage in the biocomposite composition, the mechanical strength and biodegradation of produced composites was improved but moisture properties decreased.

3. By adding and increasing the starch powder (SP) weight percentage in the biocomposite composition, all tested mechanical strengths except the tensile strength and biodegradation of produced composites were improved

4. The highest biodegradability was observed in the biocomposite consisting of the highest MCC (6\%) and SP (10\%) weight percentages.

5. By increasing MCC and SP in the composites, the stress transfer and distribution ability of composites increases, leading to an increase in consistency of produced composites and the biodegradation of the surface of produced composites.

\section{REFERENCES CITED}

Aganguly, S. (2018). "Plastic pollution and its adverse impact on environment and ecosystem," in: International Conference Recent Trends in Arts, Science, Engineering and Technology, Perambular, India, pp. 15-16.

Arjmandi, R., Hassan, A., Mohamad Haafiz, M. K., and Zakaria, Z. (2015). "Effect of microcrystalline cellulose on biodegradability, tensile and morphological properties of montmorillonite reinforced polylactic acid nanocomposites," Fibers and Polymers 16(10), 2284-2293. DOI: 10.1007/s12221-015-5507-3

Arutchelvi, J., Sudhakar, M., Arkatkat, A., Doble, M., Bhaduri, P., and Uppara, P. (2008). "Biodegradation of polyethylene and polypropylene," Indian Journal of Biotechnology 7(1), 9-22. 
Ashori, A. (2012). "Effects of nanoparticles on the mechanical properties of rice straw/ polypropylene composite," Journal of Composite Materials 47(2), 149-154. DOI:

$10.1177 / 0021998312437234$

Ashori, A. (2008). "Wood- plastic composites as promising green-composites for automotive industries!," Bioresource Technology 99(11), 4661-4667.

DOI: 10.1016/j.biortech.2007.09.043

Ashori, A., and Nourbakhsh, A. (2010). "Performance properties of microcrystalline cellulose as reinforcing agent in wood plastic composites," Composites: Part B 14(2010), 578-581. DOI: 10.1016/j.compositesb.2010.05.004

Bai, W., and Li, K. (2009). "Partial replacement of silica with microcrystalline cellulose in rubber composites," Composites Part A 40(10), 1597-1605. DOI:

10.1016/j.compositesa.2009.07.006

Beg, M. D. H., Kormin, S., Bijarimi, M., and Zaman, H. U. ( 2016). "Preparation and characterization of low-density polyethylene/thermoplastic starch composites," Advances in Polymer Technology 35(1), 1-9. DOI: 10.1002/adv.21521

Behjat, T., Russly, A. R., Lugman, C. A., Yus, A.Y., and Nor Azowa, I. (2009). "Effect of PEG on the biodegradability studies of kenaf cellulose-polyethylene composites," International Food Research Journal 16(2), 243-247. DOI: 10.13140/RG.2.1.3056.6881

Beltrami, L. V. R., Bandeira, J. A. V., Scienza, L.C., and Zattera, A. J. (2014). "Biodegradable composites: Morphological, chemical, thermal, and mechanical properties of composites of poly (hydroxybutyrate-co-hydroxyvalerate) with curaua fibers after exposure to simulated soil," Journal of Applied Polymer Science 131(17), 1-8. DOI: 10.1002/app.40712

Bhaskar, J., Haq, S., Pandey, A. K., and Srivastava, N. (2012). "Evaluation of properties of propylene- pine wood-plastic composite," Journal of Materials and Environmental Science 3(3), 605-612.

Esmaeilzadeh Saieh, S., Khademi Eslam, H., Ghasemi, E., Bazyar, B., and Rajabi, M. (2019). "Physical and morphological Effects of cellulose nano-fibers and nano-clay biodegradable WPC made of recycled starch and industrial sawdust," BioResources 14(3), 5278-5287. DOI: 10.15376/biores.14.3.5278-5287

Farsi, M. (2010). "Wood-plastic composites: Influence of wood flour chemical modification on the mechanical performance," Journal of Reinforced Plastic and Composites 29(24), 3587-3592. DOI: 10.1177/0731684410378779

Gozdecki, C., and Wilczynski, A. (2015). "Effect of wood flour type on flexural properties of wood-plastic composites," Forestry and Wood Technology 89 (2015), 50-54.

Hindi, Sh. S. Z. (2016). "Microcrystalline cellulose: Its processing and pharmaceutical specifications," BioCrystals Journal 1(1), 26-38.

Khoramnejadian, S. (2013). "Microbial degradation of starch based polypropylene," Journal of Pure and Applied Microbiology 7(4), 2857-2860.

Kiziltas, A., Gardner, D. J., Han, Y., and Seung Yang, H. (2010). "Determining the mechanical properties of microcrystalline cellulose (MCC)-filled PET-PTT blend composites," Wood and Fiber Science 42(2), 165-176.

Klyosov, A. A. (2007). Wood-Plastic Composites, Wiley, Hoboken, NJ, USA. 
Kokta, B. V., Raj, R. G., and Daneault, C. (1989). "Use of wood flour as filler in polypropylene: Studies on mechanical properties," Polymer-Plastic Technology and Engineering 28(3), 247-259. 10.1080/03602558908048598

Kormin, Sh., Kormin, F., Dalour Hossen Beg, M., and Bijarimi Mat Piah, M. (2017). "Physical and mechanical properties of LDPE incorporated with different starch sources," International Research and Innovation Summit (IRIS 2017), IOP Conf, Series: Materials Science and Engineering 226(2017) 012157, 1-9. DOI: 10.1088/1757-899X/226/1/012157

Lin, Z., Renneckar, S., and Hindman, D. P. (2008). "Nanocomposite based lignocellulosic fibers.1. Thermal stability of modified fibers with clay-polyelectrolyte multilayers," Cellulose 15(2), 333-346. DOI: 10.1007/s10570-007-9188-y

Liu, W., Wang, Y., and Sun, Z. (2003). "Effects of polyethylene-grafted maleic anhydride (PEg-MA) on thermal properties, morphology and tensile properties of low density polyethylene (LDPE) and corn starch blends," Journal of Applied Polymer Science 88(13), 2904-2911.

Lu, J. Z., Wu, Q., and McNabb, H. S. (2000). "Chemical coupling in wood fiber and polymer composites: A review of coupling agents and treatments," Wood Fiber Science 32(1), 88-104.

Madsen, B., and Gamstedt, E. K. (2013). "Wood versus plant fibers: Similarities and differences in composite applications," Advances in Materials Science and Engineering 2013 (564346), 1-14. DOI: 10.1155/2013/564346

Matzinos, P., Bikiaris, D., and Panayiotou, C. (2001). "Processing and characterization of LDPE/starch products," Journal of Applied Polymer Science 79, 2548-2557. DOI: 10.1002/1097-4628(20010401)79:14<2548::AID-APP1064>3.0.CO;2-3

Michad Gould, J., Gordon, S. H., Dexter, L. B., and Swanson, C. L. (1990). "Biodegradation of starch-containing plastic," Agricultural and Synthetic Polymers 1990 (433), 65-75.

Mijiyawa, F., Koffi, D., Kokta, B.V., and Erchiqui, F. (2014). "Formulation and tensile characterization of wood-plastic composites: Polypropylene reinforced by birch and aspen fibers for gear applications," Journal of Thermoplastic Composite Materials 28(12), 1-18. DOI: 10.1177/0892705714563120

Mousavi, S. M., Arjmandi, O., Talaghat, M. R., and Azizi, M. (2015). "Modifying the properties of polypropylene-wood composite by natural polymers and eggshell nanoparticles," Polymers from Renewable Resources 6(4), 157-174. DOI: 10.1177/204124791500600403

Muniyasamy, S., Anstey, A., Reddy, M., Misra, M., and Mohanty, A. (2013). "Biodegradability and compostability of lignocellulosic based composite materials," Journal of Renewable Materials 1(4), 253-272. DOI: 10.7569/JRM.2013.634117

Myilsamy, D., Gowtham, S., Saravanakumar, J., and Rajendran, D. (2018). "Studies on blending properties of poly lactic acid and starch with methylene diphenyl diisocyanate," International Advanced Research Journal in Sience Engineering and Technology 5 (9), 107-110. DOI: 10.17148/IARJSET.2018.5915

Nasution, H., Yurnaliza, H., Veronich, H., Irmadani, H., and Sitompul, S. (2017). "Physicochemical properties and characteristics of microcrystalline cellulose derived from the cellulose of oil palm empty fruit bunch," IOP Conf. Series: Materials Science and Engineering 223 (2017) 012056. DOI: 10.1088/1757$899 X / 223 / 1 / 012056$ 
Nourbakhsh, A., Ashori, A., and Kazemi Tabrizi, A. (2014). "Characterization and biodegradability of polypropylene composites using agricultural residues and waste fish," Composites: Part B 56 (2014), 279-283. DOI: 10.1016/j.compositesb.2013.08.028

Oduola, M. K., and Akpeji, P. O. (2015). "Effects of starch on the Mechanical and Rheological properties pf polypropylene," American Journal of Chemical Engineering 3(2-1), 1-8. DOI: 10.11648/j.ajche.s.2015030201.11

Oladayo, O. O., Umunna Queendaline, C., Olusegun Sunday, J., and Oluwasegun, W. (2016). "Physicochemical properties of cassava starch and starch- keratin prepared biofilm," Songklanakarin Journal of Science and Technology 38(4), 349-355. DOI: 10.14456/sjst-psu.2016.47

Salemane, M. G., and Luyt, A. S. (2006). "Thermal and mechanical properties of polypropylene-wood powder composites," Applied Polymer Science 100 (5), 41734180. DOI: 10.1002/app.23521

Shah, P., and Pendey, K. (2017). "Advancement in packaging film using microcrystalline cellulose and $\mathrm{TiO}_{2}$," American Journal of Polymer Science and Technology 3(6), 97 102. DOI: $10.11648 /$ j.ajpst.20170306.11

Stark, N. M., and Rowlands, R. E. (2003). "Effects of wood fiber characteristics on mechanical properties of wood/ polypropylene composites," Wood and Fiber Science 35(2), 167-174.

Subba Reddy, M., Sriniv Asulu Reddy, P., Venkata Subbaiah, G., and Venkata Subbaiah, H. (2014). "Effect of plastic pollution on environment," Journal of Chemical and Pharmaceutical Sciences Special Issue 2014, 28-29.

Suharty, N. S., Mathialagan, M., Ismail, H., Wirjosentono, B., Firdaus, M., and Wardani, G. K. (2014). "Tensile properties and biodegradability of rice husk powder-filled recycled polypropylene composites: Effect of crude palm oil and trimethylolpropane triacrylate," Journal of Physical Science 25(2), 55-71.

Tabarsa, T., Khanjanzadeh, H., and Pirayesh, H. (2011). "Manufacturing of wood- plastic composite from completely recycled materials," Key Engineering Materials 471472(2011), 62-66. DOI: 10.4028/www.scientific.net/ KEM. 471-472.62

Tay, C. C., Mohd, S. O., and Sinin, H. (2014). "Water absorption and thickness swelling behavior of sago particles urea formaldehyde particleboard," International Journal of Science and Research (IJSR) 3(12), 1375-1379.

Todor, M. P., Bulei, C., Heput, T., and Kiss, I. (2018). "Researches on the development of new composite materials complete/ partially biodegradable using natural textile fibers of new vegetable origin and those recovered from textile waste," IOP Conf. Series: Materials Science and Engineering 294 (2018) 012021. DOI: 10.1088/1757899X/294/1/012021

Verma, P., Dixit, S., and Asokan, P. (2013). "Biodegradation of coir/ epoxy composites," Applied Polymer Composites 1(2), 75-84.

Wang, X., Chai, Y., and Liu, J. (2013). "Formation of highly hydrophobic wood surfaces using silica nanoparticles modified with long- chain alkylsilane," Holzforschung 67(6), 667-672. DOI: 10.1515/hf-2012-0153

Wilfred, O., Tai, H., Marriott, R., Liu, Q., Teverezovskiy, V., Curling, S., Tai, H., Fan, Zh., and Wang, W. (2018).'Biodegradation of polylactic acid and starch composites in compost and soil," International Journal of Nano Research 1(2), 01-11. 
Zuchowska, D., Steller, R., and Meissner, W. (1998). "Structure and properties of degradable polyolefin-starch blends," Polymer Degradation and Stability 60(2-3), 471-480. DOI: 10.1016/S0141-3910(97)00110-9

Article submitted: November 30, 2019; Peer review completed: February 1, 2020; Revised version received and accepted: March 19, 2020; Published: April 15, 2020.

DOI: 10.15376/biores.15.2.4188-4204 